\title{
Stress loading and the occurrence of normal-type earthquakes under Boso Peninsula, Japan
}

\author{
Akinori Hashima $^{1 *} \mathbb{D}$, Hiroshi Sato ${ }^{1}$ and Toshinori Sato ${ }^{2}$
}

\begin{abstract}
Boso Peninsula, Japan, was formed by the interaction of the Philippine Sea, Eurasian and Pacific plates around the trench-trench-trench Boso triple junction. Normal-type earthquakes are persistently observed in the subducting Philippine Sea slab under the peninsula at a depth of $\sim 30 \mathrm{~km}$, including a recent (2019) $M_{w} 4.9$ earthquake which caused shaking throughout the Kanto region (greater Tokyo). Such shallow intraplate earthquakes are potentially hazardous to this heavily populated region, yet their mechanism is poorly understood, especially in the context of a three-plate system. Here, we calculate stress rates in the Philippine Sea slab and the surrounding area, using a subduction model constructed in a previous study, to explain the generation of the regional stress field and its effect on earthquake occurrence. In general, the calculated stress rates under Boso Peninsula are horizontally extensional both above and below the Eurasian-Philippine Sea plate interface. We apply our calculated stress rates to the nodal planes of the observed earthquakes to calculate the Coulomb failure function ( $\triangle C F F$ ). These calculated $\triangle C F F s$ are generally positive on normal-type earthquakes under Boso. The $\triangle C F F$ s are also consistent with earthquakes in adjacent areas that are seismically active, for example, in the Philippine Sea plate to the south, in the collision zone around Izu Peninsula, and in the cluster in the Eurasian plate northeast of Boso Peninsula, which further supports our stress loading model. Calculation of the individual contributions of Philippine Sea plate and Pacific plate subduction shows that the development of the stress field around Boso is dependent upon contributions from both subducting plates. In contrast, the arc-arc collision at Izu Peninsula has little influence.
\end{abstract}

Keywords: Stress loading, Philippine Sea plate, Boso Peninsula, Intra-slab earthquake, Plate subduction, Elastic dislocation theory

\section{Introduction}

Off Boso Peninsula in central Japan, the Eurasian (EUR), Philippine Sea (PHS) and Pacific (PAC) plates meet to form a unique trench-trench-trench triple junction. The closest onshore expression of this triple junction is Boso Peninsula itself, which lies on the uppermost EUR plate. It is marked by a rapid Holocene uplift rate of up to $5 \mathrm{~mm}$ /year, estimated from the height of paleo-shorelines (Koike and Machida 2001).

\footnotetext{
*Correspondence: hashima@eri.u-tokyo.ac.jp

${ }^{1}$ Earthquake Research Institute, University of Tokyo, Yayoi 1-1-1,

Bunkyo-ku, Tokyo 113-0032, Japan

Full list of author information is available at the end of the article
}

Under the peninsula, normal-type earthquakes are persistently observed in the subducting PHS slab at a depth of $\sim 30 \mathrm{~km}$ (Nakajima et al. 2011; Imanishi et al. 2019). A recent example is the 2019 May $25 M_{\mathrm{w}} 4.9$ earthquake (Fig. 1), from which moderate shaking was felt throughout the Tokyo metropolitan area, in the Kanto Basin.

The occurrence of normal-type earthquakes in an overriding plate appears contradictory in a convergent plate setting. Nevertheless, normal-type earthquakes in subduction zones worldwide occur around major extensional structures, typically backarc basins such as the Mariana trough, the Lau Basin, and the Aegean Sea. In addition, earthquakes beneath the outer rise in subducting slabs are mostly normal-type, ascribed to slab 

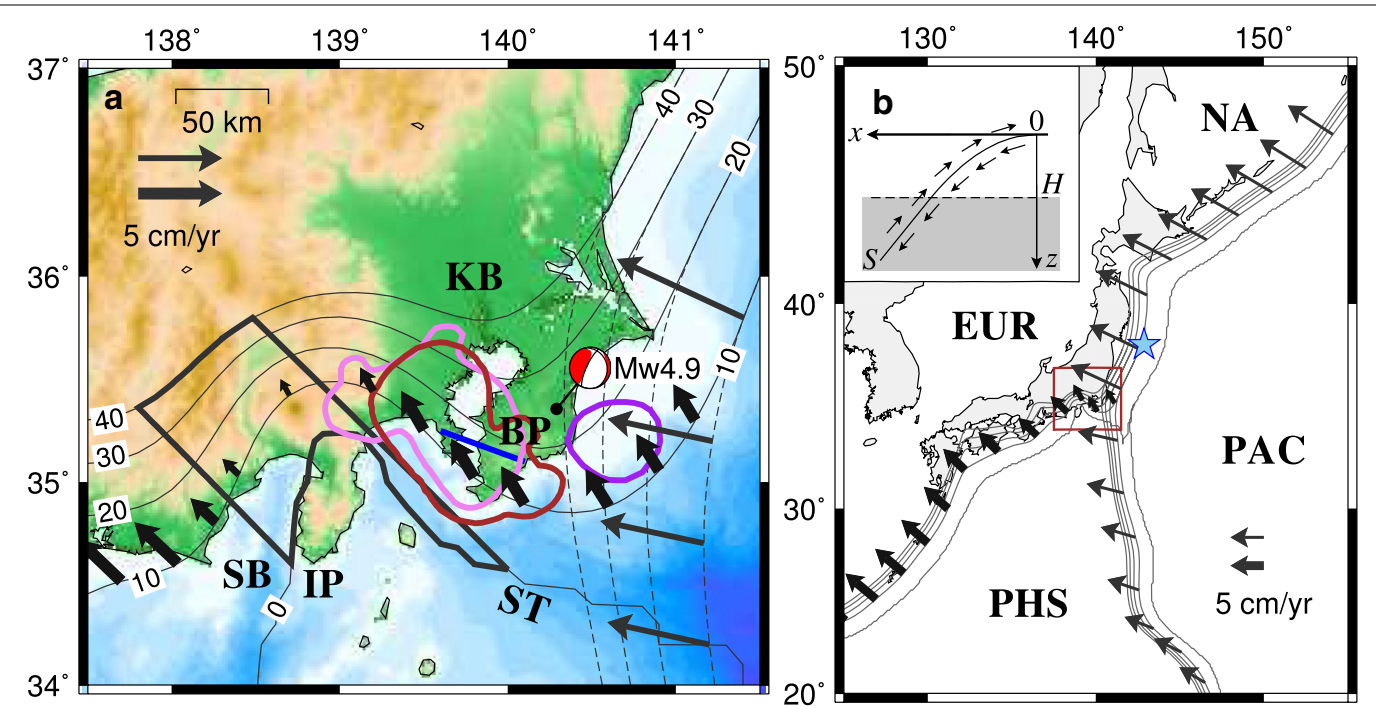

Fig. 1 a Landforms around Boso Peninsula (BP) and the Kanto Basin (KB). Topography data from Smith and Sandwell (1997). IP: Izu Peninsula, SB: Suruga Bay, ST: Sagami Trough. Solid contours map upper surface of PHS plate, and dashed contours, upper surface of PAC plate. Blue line indicates structural high bounding forearc basin and trench slope. Focal mechanism marks location of $M_{w} 4.9$ normal-type earthquake of 2019/05/25. Thick black outline indicates best estimate of locked zone due to collision of the Izu-Bonin arc at Izu Peninsula (Hashima et al. 2016). Colored outlines show source/slip areas for 1703 Kanto earthquake (red) (Sato et al. 2016), 1923 Kanto earthquake (pink) (Matsu'ura et al. 2007), and Boso slow slip zone (purple) (Sato et al. 2017). b Slip rate distribution on plate interfaces around Japan used in our computations. Contours denote upper surfaces of PHS and PAC plates. Slip rates for PHS plate (thick arrow) and PAC plate (thin arrow) based on NUVEL-1A model (DeMets et al. 1994). 3-D plate interface data from CAMP model (Hashimoto et al. 2004). Star: hypocenter, 2011 M9 Tohoku earthquake. Red rectangle indicates area shown in a. Inset: Schematic illustration of internal structure and slip distribution in vertical section perpendicular to the trench. See text for parameter $H$ and $S$

bending (Christensen and Ruff, 1988). Below $70 \mathrm{~km}$ depth, unbending results in a double-seismic zone, with compressive earthquakes in the upper part of the slab and extensional below. (Engdahl and Scholz 1977; Hasegawa et al. 1978). Between depths of 20 and $70 \mathrm{~km}$, shallow slabs are generally considered to be in a neutral stress state, although Seno and Yoshida (2004) found that earthquakes of $M \geq 7$, mostly normal type, occur in this depth range in circum-Pacific slabs. They suggested that the character of intra-slab activity may be linked to a pattern of increasing compression from arc to trench, which indicates the importance of considering plate-toplate interactions in the context of the whole system on generating intraplate stress.

The Japanese islands are dominated by reverse or strike-slip type earthquakes except in the Okinawa trough or the Beppu-Shimabara graben, where extensional structures develop (e.g. Terakawa and Matsu'ura 2010). Upon closer look, however, there are minor clusters of normal-type earthquakes elsewhere. In the Fukushima coastal area, normal-type events, including the $M_{\mathrm{w}} 6.6$ Iwaki earthquake, were activated after the 2011 Tohoku earthquake, where previously the area had been calm with tiny extensional events (Imanishi et al. 2012). At Boso Peninsula, minor clusters of normal-type earthquakes occur, mixed with other type events (Imanishi et al. 2019).

Intraplate earthquakes are considered to release the stress which has been gradually accumulated over thousands of years through steady plate subduction. However, under Boso, the loading mechanism on these potentially hazardous, shallow, intra-slab earthquakes is less wellunderstood because of the additional complication of the three-plate setting.

To intuitively understand and quantitatively estimate a loading mechanism of this kind, modeling is a useful approach. Mechanical modeling of plate subduction has been developed to explain the dynamics of slab behaviors in a crust-mantle system, including slab rollback that leads to extension in the overriding plate (e.g., Funiciello et al. 2003; Enns et al. 2005; Holt et al. 2018). However, the resolution of this approach is too low for the purposes of this study. Sato and Matsu'ura (1988) and Matsu'ura and Sato (1989) developed a dislocation model for steady plate subduction where relative slip is kinematically assigned to the known plate interface. Internal deformation and stress are then solved as a boundary problem of an elastic-viscoelastic Earth. The dislocation model can be easily applied to a 3-D plate interface. Hashimoto et al. (2004) and Hashimoto and Matsu'ura (2006) made 3-D 
simulations for vertical displacements and stress rates around Japan, showing an overall match with observation. Takada and Matsu'ura (2004) and Hashimoto and Matsu'ura (2006) extended the model to treat continental collision by adding a slip-rate deficit to steady subduction. In contrast, Hashima et al. (2008a) showed that sliprate excess (forward slip) produces backarc extension. Recently, Fukahata and Matsu'ura (2016) theoretically proved that simple 2-D subduction leads to extension in the overriding plate.

In a previous study, we developed a dislocation model for the subduction of both the PHS and PAC plates and the collision of the Izu-Bonin (Ogasawara) arc using onshore geological constraints for the last $1 \mathrm{Myr}$ (Hashima et al. 2016). Here, we use this model to explain the development of the stress field around Boso Peninsula, and then discuss its relationship to seismicity.

\section{Tectonic setting around Boso Peninsula}

Boso Peninsula is part of the Kanto basin system (Fig. 1a), which developed as a forearc basin as a result of subduction of both the PAC and PHS plates (Matsuda 1991). It is now covered by thick Cenozoic sediments. An eastwest trending structural high cuts across southern Boso Peninsula at $35.2^{\circ} \mathrm{N}$, bounding the forearc basin and the trench slope. The development of the Kanto Basin system has been also strongly affected from the west by the arcarc collision at Izu Peninsula, which was originally part of the Izu-Bonin arc (Sugimura 1972; Matsuda 1978).

Presently, the PHS plate subducts northwestward under the Sagami trough at a rate of $\sim 3 \mathrm{~cm} /$ year, while the PAC plate subducts from the east at $\sim 8 \mathrm{~cm} /$ year (Fig. 1). The Sagami trough is known to have hosted M8-class Kanto earthquakes west of Boso Peninsula in 1923 and 1703 (Fig. 1a). Based upon an earthquake cycle model with viscoelastic media, the recurrence interval of these events was estimated to be 350 years (Sato et al. 2016). To the east of Boso, seismic activity is of a different character, with $\sim$ M6 slow-slip events (Fig. 1a) occurring approximately every 6 years (Ozawa et al. 2003; Sato et al. 2017). Further north, the Japan trench was ruptured by the 2011 M9 Tohoku earthquake (Fig. 1b), which significantly affected seismicity around the Kanto basin (Ishibe et al. 2011, 2015).

To characterize seismic activity around the Kanto Basin, we take shallow $(\leq 40 \mathrm{~km})$ moment tensors of magnitude $M_{\mathrm{w}}>3.5$, with a variance reduction of $\geq 70 \%$, for the period 1 January 2003 to 30 September 2019 from the F-net focal mechanism catalog of the National Research Institute for Earth Science and Disaster Resilience (NIED) (Okada et al. 2004). Using the geometry of the plate interface from the CAMP model of Hashimoto et al. (2004), we divide the earthquakes into PHS, EUR, and PAC earthquakes according to their location. Then, we exclude PAC earthquakes. The number of the PHS and EUR earthquakes is 196 and 202. It should be noted that we do not distinguish between inter- and intraplate earthquakes with this classification because it is difficult to identify a single EUR-PHS interface due to a scarcity of earthquakes with clear thrust-type mechanisms in the F-net catalog. Indeed, the position of the EURPHS interface under the Boso Peninsula varies widely among different studies (Nakajima et al. 2009 and references therein). It is possible that our classification which relies on a plate interface model may thus introduce a bias in interpreting the overall mechanism pattern, given the ambiguity of distinguishing inter- and intraplate earthquakes.

For the purposes of our plots, moment tensors $\tau_{i j}$ are classified in terms of mean horizontal normal component $\tau_{m}=\left(\tau_{11}+\tau_{22}\right) / 2$, where directions 1,2 , and 3 denote east, north, and up, respectively. The moment tensors are normalized as $\tau_{i j}^{\prime}=\tau_{i j} /|\boldsymbol{\tau}|$ with $|\boldsymbol{\tau}|=\sqrt{\sum_{i} \sum_{j} \tau_{i j}}$. Thus, the normalized mean horizontal moment tensor $\tau_{m}^{\prime}=\left(\tau_{11}^{\prime}+\tau_{22}^{\prime}\right) / 2$ varies from -0.5 to 0.5 . Positive values denote horizontal extension and negative values denote horizontal compression, which correspond to normal- and reverse-type events, with strike-slip type events falling in between.

Figure 2 shows the PHS and EUR earthquakes in map and side view; the inset histogram is plotted with respect to $\tau_{m}^{\prime}$. We find that the east coast of Boso Peninsula is seismically active in both the hanging wall and foot wall of the plate interface. Normal-type earthquakes occur on the PHS side (Fig. 2a), showing northwest-southeast extension. Normal-type earthquakes are also found in the upper plate (EUR) (Fig. 2b), although the population is more mixed with reverse types. To show the detailed vertical distribution of fault types around Boso, we plot north-south cross-sections between $139.9^{\circ} \mathrm{E}$ and $140.5^{\circ}$ $E$, which we separate into two periods, before and after the 2011 Tohoku earthquake (Fig. 2c, d). In terms of seismicity, the PHS plate is more seismically active than the EUR plate before the M9, but less active after, while the fault types remain basically the same (Ishibe et al. 2011, 2015). Their frequency distribution with respect to $\tau_{m}^{\prime}$ shows the superiority of the compressional-type earthquakes especially after the 2011 Tohoku earthquake, but most of them occur close to the plate interface (Fig. 2c, d). In both periods, we see the broad occurrence of normal-type earthquakes above and below the PHS upper surface. From this distribution, we infer that stress states in the both EUR and PHS plates favor normal-type earthquakes. In contrast, reverse-type earthquakes, which prevail around $35.4^{\circ} \mathrm{N}$ into the PHS plate, can be viewed 


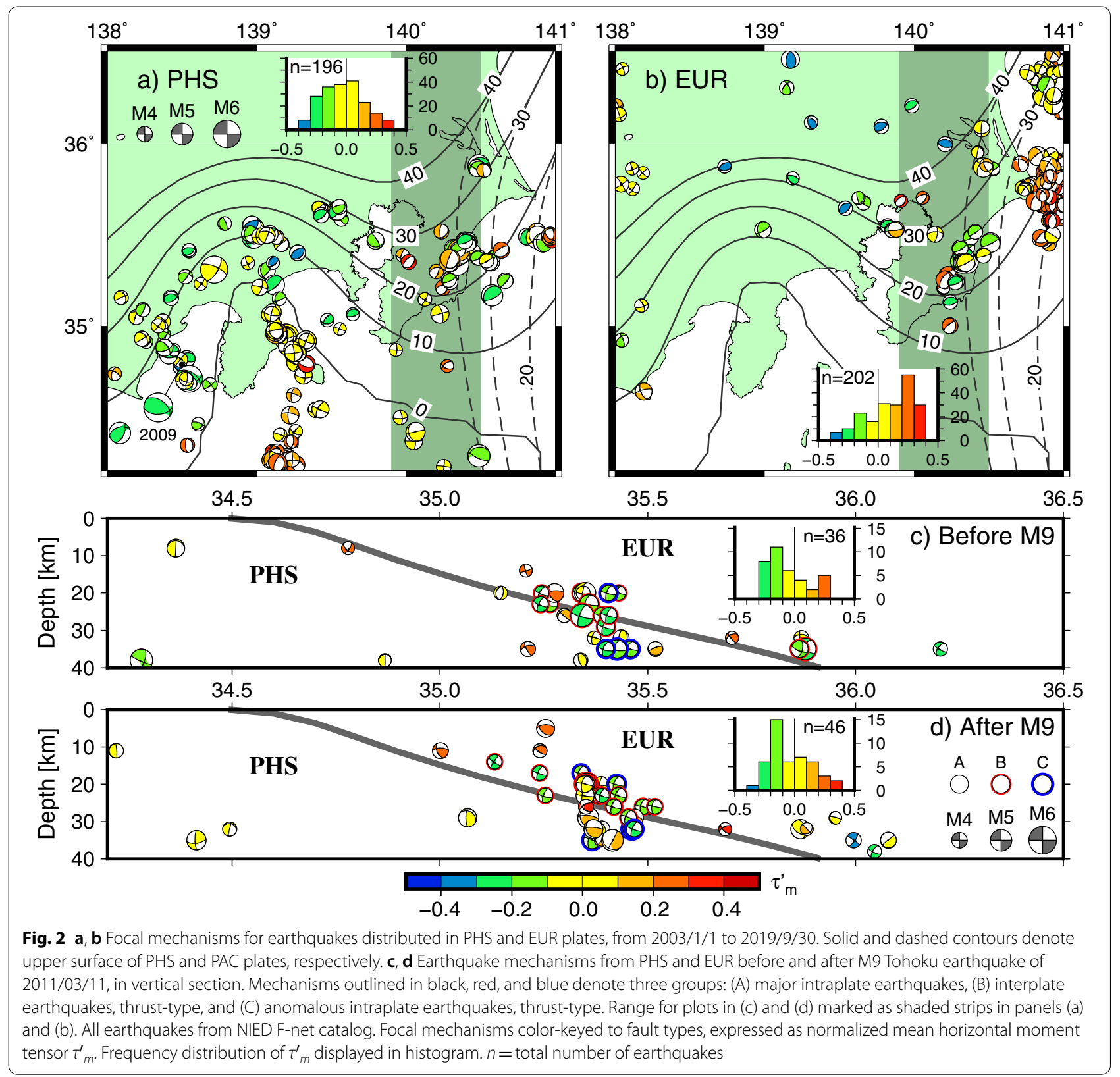

as an anomalous localized activity. South of the Sagami trough $\left(<34.5^{\circ} \mathrm{N}\right)$, strike-slip type earthquakes dominate with an extension axis normal to the Sagami trough.

Subsequently, we re-classify the earthquakes around Boso (Fig. 2c, d) into three groups: (A) major intraplate earthquakes, (B) interplate earthquakes, and (C) anomalous reverse-type earthquakes around $35.4^{\circ} \mathrm{N}$. Group B is defined by thrust events $\left(\tau_{m}^{\prime}<-0.1\right)$ located within $5 \mathrm{~km}$ of the EUR-PHS plate interface of the CAMP model. Group $\mathrm{C}$ is defined by non-interplate events with $\tau_{m}^{\prime}<-0.1$ located between $35.3^{\circ} \mathrm{N}$ and $35.5^{\circ} \mathrm{N}$ latitude. The rest fall into Group A. The number of events of
Groups A, B, and C is 19, 13, and 4, respectively, before the 2011 Tohoku earthquake and 26, 15, and 5, respectively, after the Tohoku earthquake.

To the west, in the PHS plate, we see seismicity around Izu Peninsula related to the arc-arc collision (Fig. 2a). Seismic activity along the longitude of $139^{\circ} \mathrm{E}$ varies from reverse-type at around $35.5^{\circ} \mathrm{N}$ to strike-slip type at around $34.5^{\circ} \mathrm{N}$ but the compressive axis is commonly northwest-southeast. The southernmost cluster is mostly related to volcanic activities but may reflect the regional stress field. The cluster around $\left(138.5^{\circ} \mathrm{E}, 34.8^{\circ} \mathrm{N}\right)$ in Suruga Bay comprises mostly aftershocks from the 2009 
M6.5 earthquake (Fig. 2a). On the EUR side of the Izu collision zone, seismicity is much sparser (Fig. 2b), but we can see that the compressive quadrants trend from E-W and NW-SE around $138^{\circ} \mathrm{E}$ to $\mathrm{N}-\mathrm{S}$ around $139^{\circ} \mathrm{E}$ [the event at $\left(139^{\circ} \mathrm{E}, 35.5^{\circ} \mathrm{N}\right)$ may be negligible because it is likely an interplate event]. This trend, presumably related to the Izu collision, is consistent with a radial stress pattern estimated from surface fault traces (Matsuda 1977). There is also a large cluster of seismicity northeast of Boso Peninsula around $141^{\circ} \mathrm{E}$ in the EUR plate (Fig. 2b), but most of this activity occurred after the 2011 Tohoku earthquake.

\section{Model setting}

Following Hashimoto et al. (2004) and Hashima et al. (2016), we compute the internal stress accumulation rates due to steady subduction of the PHS and PAC plates and the collision of Izu Peninsula.

We adopt the CAMP standard model for the 3-D geometry of the upper surfaces of the PHS and PAC plates around Japan (Hashimoto et al. 2004). Geographic coordinates are transformed into local Cartesian coordinates using the Lambert conformal conic projection with a central point $\left(35^{\circ} \mathrm{N}, 140^{\circ} \mathrm{E}\right)$ and standard parallels $30^{\circ}$ $\mathrm{N}$ and $40^{\circ} \mathrm{N}$. Then, we assign slip vectors on the plate interfaces projected from the NUVEL-1A surface plate motion (DeMets et al. 1994) (Fig. 1b) by the projection method of Hashimoto et al. (2004).

Around Izu Peninsula, steady plate subduction is impeded by the buoyancy of the Izu-Bonin arc crust. According to Takada and Matsu'ura (2004) and Hashimoto and Matsu'ura (2006), this effect can be represented as a permanent slip deficit. In this study, we use the distribution of the slip-rate deficit in the final stage of the 1 Myr-long rotation of the slip-rate deficit zone (locked zone) presented in Fig. 8d of Hashima et al. (2016) (Fig. 1a), which is determined by geomorphological, geological, and thermochronological constraints. In this stage, the locked zone is mainly located to the northwest of Izu Peninsula with an east-west width of $110 \mathrm{~km}$. The collision rate (slip-deficit rate/convergence rate) is assumed to be 1 (fully locked) in the locked zone.

The material structure is assumed to be an elastic-viscoelastic layered half-space with an elastic thickness, $H=40 \mathrm{~km}$ (inset in Fig. 1b), corresponding to the lithosphere-asthenosphere system. The elastic parameters and viscosity are the same values as those used in Hashimoto et al. (2004) and Hashima et al. (2016): $\rho_{\mathrm{L}}=3000 \mathrm{~kg} /$ $\mathrm{m}^{3}, \quad K_{\mathrm{L}}=66.7 \mathrm{GPa}, \mu_{\mathrm{L}}=40 \quad \mathrm{GPa}, \rho_{\mathrm{A}}=3400 \mathrm{~kg} / \mathrm{m}^{3}$, $K_{\mathrm{A}}=130 \mathrm{GPa}, \mu_{\mathrm{A}}=60 \mathrm{GPa}$, and $\eta=5 \times 10^{18} \mathrm{~Pa} \mathrm{~s}$, where $\rho, K, \mu$, and $\eta$ denote density, bulk modulus, rigidity, and viscosity, respectively, with subscripts $\mathrm{L}$ and A denoting lithosphere and asthenosphere.
Following Sato and Matsu'ura (1988), we calculate the stress rate $\sigma_{i j}(\mathbf{x})$ in the plate interior for steady slip rates $w_{k}(\boldsymbol{\xi})$ assigned over the plate interfaces $S(\boldsymbol{\xi})$ as follows:

$$
\sigma_{i j}(\mathbf{x})=\int_{S(\xi)} G_{i j k}(\mathbf{x}, t=\infty ; \xi, 0) w_{k}(\xi) \mathrm{d} \xi
$$

where $G_{i j k}(\mathbf{x}, t=\infty ; \boldsymbol{\xi}, 0)$ denotes the final state $(t=\infty)$ of the stress response to a unit slip in the $k$-direction. The explicit expressions for $G_{i j k}(\mathbf{x}, t=\infty ; \boldsymbol{\xi}, 0)$ are derived by Fukahata and Matsu'ura $(2005,2006)$, and Hashima et al. (2008b, 2014). The equivalence theorem of Fukahata and Matsu'ura (2006) is also applied to efficiently compute the final state of the viscoelastic response. The calculated stress rate is gradually accumulated within the plate to develop the regional stress field as steady plate subduction proceeds, while the effects of repeated locking and rupture at the plate interface are canceled in the long term (Sato and Matsu'ura 1988; Matsu'ura and Sato 1989).

There are several ways to examine the match between the calculated stress loading rates $\sigma_{i j}$ and the observed earthquakes (Fig. 2), which release stress. The easiest way might be to compare directly the calculated stress loading rates and the observed moment tensor, assuming long-term balance and statistical consistency. However, individual moment tensors are not strictly equal to the released stress itself and may also be affected by the factors like local weak planes or variable pore pressure values. In this study, we evaluate the Coulomb failure function $(\triangle \mathrm{CFF})$ for the nodal plane of each earthquake. $\Delta C F F$ denotes the preference of loaded stress for the rupture of a fault, which is simply defined by the difference between loaded shear stress and fault strength as

$$
\Delta \mathrm{CFF}=\sigma_{\mathrm{s}}-\mu^{\prime} \sigma_{\mathrm{n}} \text { with } \sigma_{\mathrm{s}}=\sigma_{i j} n_{j} v_{i}, \sigma_{\mathrm{n}}=-\sigma_{i j} n_{j} n_{i},
$$

where $\sigma_{\mathrm{s}}$ and $\sigma_{\mathrm{n}}$ are the shear and normal (positive in compression) stress on the fault plane, respectively, and where normal vector $n_{i}$ and slip direction vector $v_{i} \cdot n_{i}$ and $v_{i}$ can be obtained by the strike, dip, and rake of the nodal plane in the F-net catalog; $\mu^{\prime}$ is the apparent friction coefficient. We assume a standard value of 0.4 for $\mu^{\prime}$. Positive $\Delta C F F$ indicates that the fault shifts closer to rupture and negative $\triangle C F F$ indicates a shift away from rupture.

\section{Results}

Figure $3 \mathrm{a}, \mathrm{b}$ shows the calculated stress rates at depths of $10 \mathrm{~km}$ and $30 \mathrm{~km}$, which correspond to the stress above and below the PHS plate interface around Boso Peninsula. Figure 3a is the same result as Fig. 10a of Hashima et al. (2016) except that here we include the full stress components excluding the trace. Around Boso Peninsula, the calculated stress rates are largely extensional, ranging 


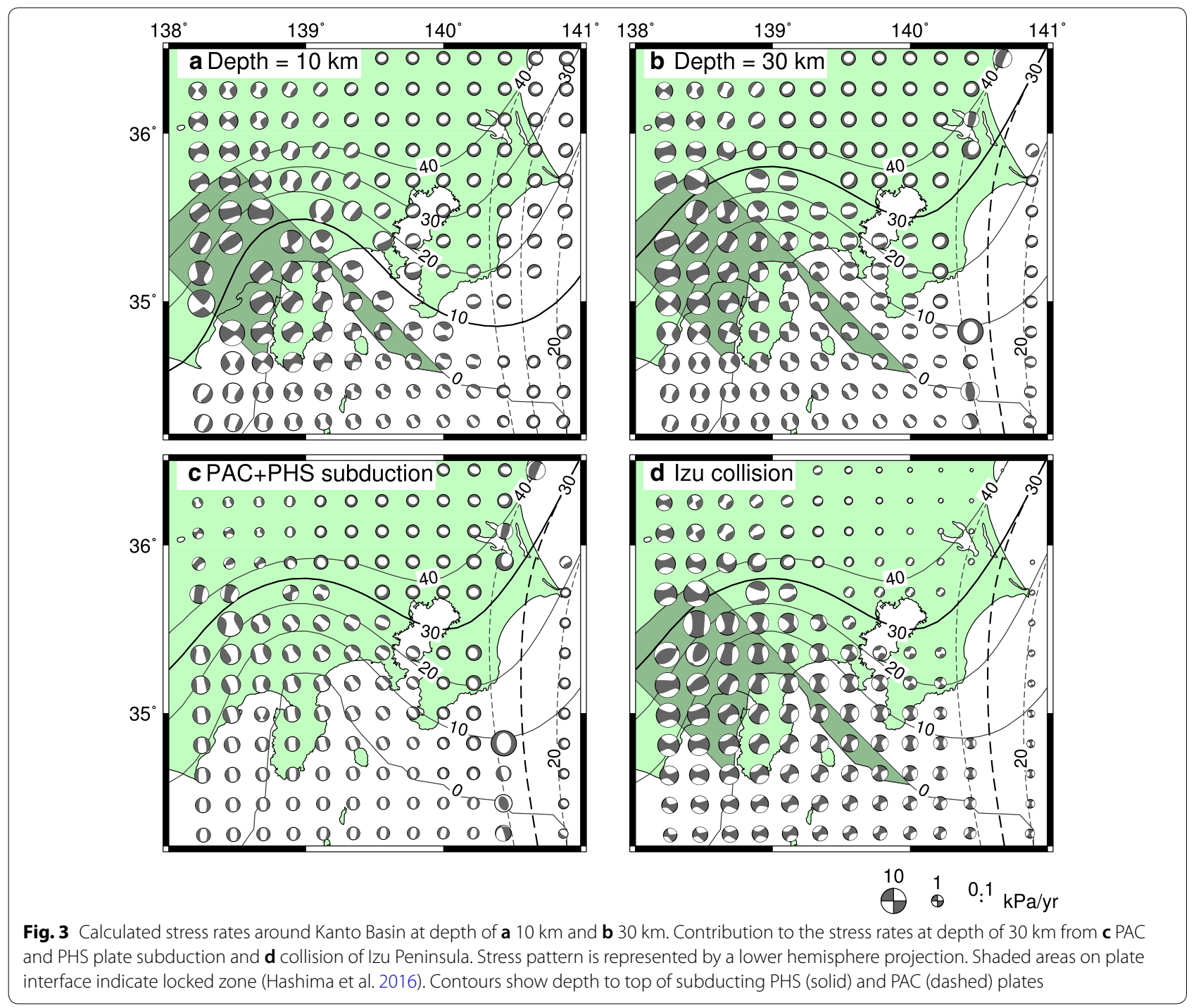

from uniaxial extension near the Sagami trough to allaround horizontal extension (represented by a doughnut-like symbol) in the Kanto Basin, with normal-type mechanisms in between. This explains the occurrence of normal-type earthquakes under Boso Peninsula. Previous stress estimates inverted from focal mechanisms show various stress types in the area under Boso Peninsula, which might be due to the inclusion of interplate events (Terakawa and Matsu'ura 2010; Imanishi et al. 2019). To the west, the calculated stress rate field also appears consistent with earthquake mechanisms and previous stress estimates around Izu Peninsula, and further south, as discussed in Hashima et al. (2016).

In Fig. 3c, d, we decompose the stress rates at $30 \mathrm{~km}$ depth into the contribution of the subduction of the PAC and PHS plates, together, and the contribution of the Izu collision. We observe that the subduction effect creates normal-type to all-around horizontal extension (Fig. 3c) while the collision effect dominates the area above the locked zone with compression (Fig. 3d). Around the eastern part of Boso Peninsula, the collision effect is smaller and may be negligible.

Figure 4 shows how the calculated stress rates match actual earthquake occurrences in terms of $\triangle$ CFF. Here, we take nodal plane 1 of the F-net catalog to compute $\triangle$ CFF. The results for nodal plane 2 show similar characteristics (Additional file 1: Fig. S1). The map-view representations (Fig. 4a, b) show generally positive $\Delta$ CFFs over our study area including those around Izu Peninsula and in Suruga Bay in the PHS plate, and in the cluster northeast of Boso Peninsula around $141^{\circ} \mathrm{E}$ on the EUR plate side. Focusing on Boso Peninsula, positive $\triangle$ CFFs appear 


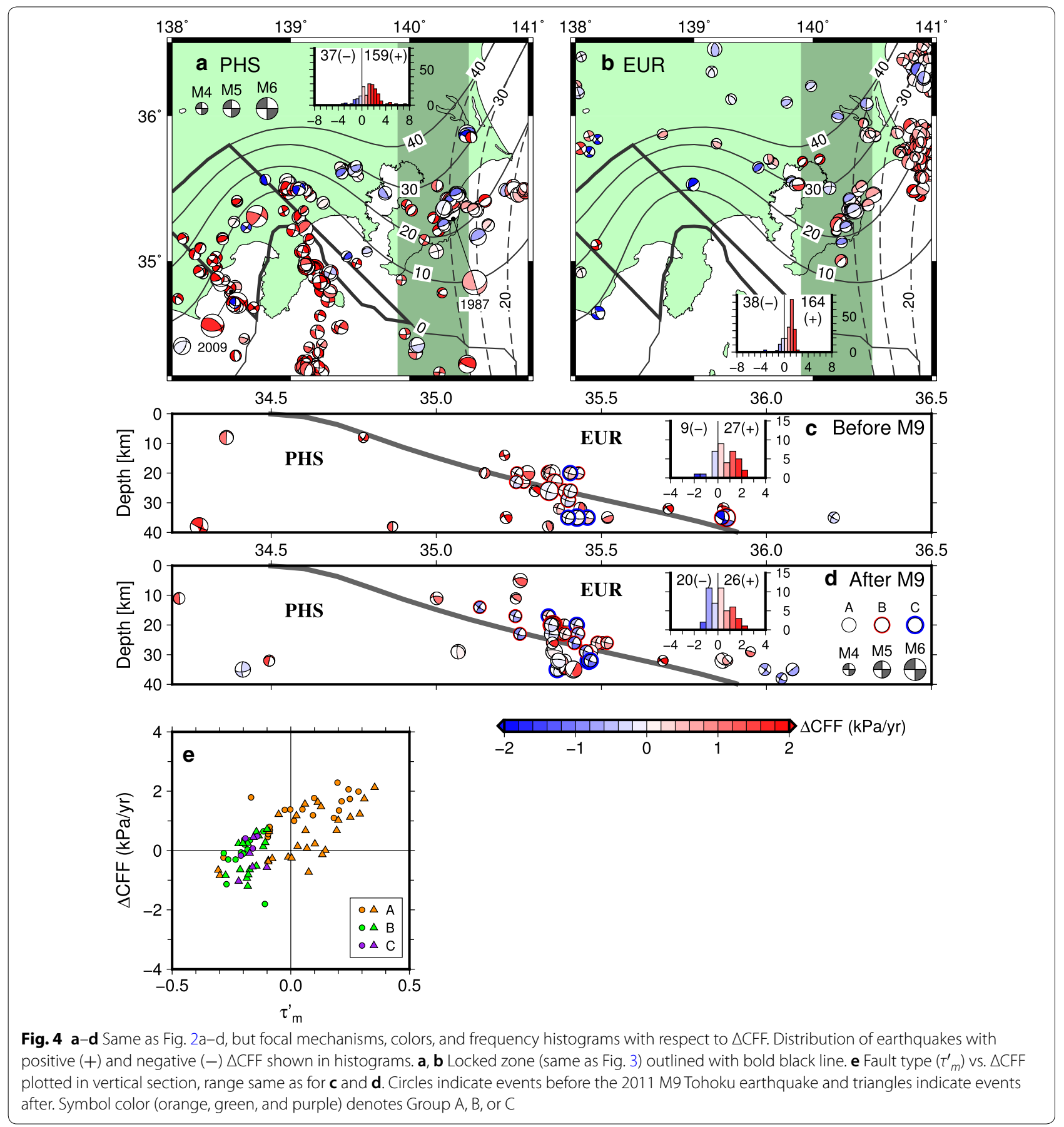

less dominant because of the active thrust events, especially for nodal plane 2 (Fig. 4c, d, Additional file 1: Fig. S1c, d). However, we can see the tendency of normal-type earthquakes both above and below the plate interface for positive $\triangle \mathrm{CFF}$ and that of thrusts, which are more concentrated on the plate interface, for negative $\triangle \mathrm{CFF}$.

To see this tendency clearly, we plotted the correlation between $\triangle \mathrm{CFF}$ and fault type in terms of normalized mean horizontal moment tensor $\tau_{m}^{\prime}$ (Fig. 4e). Group designations A, B, and C are marked by different colors, while timing before or after the 2011 Tohoku earthquake is distinguished by circles and triangles. Figure $4 \mathrm{e}$ shows a preference (positive $\triangle \mathrm{CFF}$ ) for normal-type earthquakes (positive $\tau_{m}^{\prime}$ ). In particular, Group A (major intraplate) events have mostly positive $\triangle \mathrm{CFF}$, supporting our stress loading model 
for the occurrence of normal-type earthquakes within the plate. Events with a negative $\triangle \mathrm{CFF}$ are mostly from Groups B and C, which represent interplate earthquakes and anomalous reverse-type activity, around $35.4^{\circ} \mathrm{N}$, respectively. The loading mechanism of Group $\mathrm{C}$ is unclear, but it might be related to local stress perturbations or rheological heterogeneity. Events with a positive $\triangle \mathrm{CFF}$ are also found in Groups $\mathrm{B}$ and $\mathrm{C}$, but their $\triangle \mathrm{CFF}$ values are smaller than those of Group A normal-type events. If we compare events from before and after the 2011 Tohoku earthquake, the correlation between positive $\triangle \mathrm{CFF}$ and group designation becomes less clear after 2011, probably due to external perturbation of the stress field from the M9 Tohoku earthquake.

The northern Kanto Basin around $\left(140^{\circ} \mathrm{E}, 36^{\circ} \mathrm{N}\right)$, dominated by negative $\triangle$ CFFs (Fig. $4 \mathrm{~b}$ ), is an exception because the calculated horizontal extension is inconsistent with the observed reverse-type earthquakes. Our previous study also shows a discrepancy between calculated subsidence and observed uplift in this area (Hashima et al. 2016), which can be ascribed to the omission of the effect of compression tectonics in the northeastern Japan arc (Sato 1994).

We also examined the match between stress rates and moment tensors by taking the normalized tensor dot product (Additional file 1: Fig. S2). The result is similar to Fig. 4 and Additional file 1: Fig. S1, but the correlation between the normalized tensor dot product and $\tau_{m}^{\prime}$ is more clear (Additional file 1: Fig. S2e).

\section{Discussion}

In this study, we calculated stress rates accumulated around Boso Peninsula and the Kanto Basin, based on the dislocation model that we previously developed to explain the evolution of the geological deformation pattern in this area (Hashima et al. 2016). Though the model neglects the elastic slabs under the elastic-viscoelastic boundary at depth of $40 \mathrm{~km}$, it successfully explains the observed occurrence of shallow intraplate earthquakes with normal-type mechanisms under Boso Peninsula, including the most recent $M_{\mathrm{w}} 4.9$ earthquake. This indicates the importance of steady plate subduction in stress accumulation.

Before the period covered by the F-net catalog, a moderate M 6.7 earthquake occurred in 1987 east of Boso Peninsula, resulting in injury, loss of life, and broad damage to the urban function. This earthquake is also considered an intraplate earthquake in the PHS plate. The focal mechanism is strike-slip (e.g. Okada and Kasahara 1990), but its extension axis directing northwest-southeast is similar to the normal-type earthquakes under Boso Peninsula. Nakajima et al. (2009) and Nakajima and Hasegawa (2010) pointed out that the hypocenter is located at the western boundary of the serpentinized front wedge of the PHS slab sandwiched by the EUR and PAC plates. We applied our model stress to this event, using data from the Harvard CMT catalog (Ekström et al. 2012), and obtain positive $\triangle$ CFFs for both nodal planes (Fig. 4a and Additional file 1: Fig. S1a). This result seems promising but should be carefully examined. The depth of the Harvard CMT solution is estimated to be $20 \mathrm{~km}$, much shallower than previous estimates of $40-60 \mathrm{~km}$ (e.g. Okada and Kasahara 1990) where our model would be inapplicable. If the stress field at this depth $(40-60 \mathrm{~km})$ is similar to our model results, then the 1987 earthquake could be explained with the stress loading. This should be tested in a model with elastic slabs.

The spatial range of the locked zone with the magnitude of the collision rate around Izu Peninsula is the primary control parameter of the model. In this study, we adopted Hashima et al. (2016)'s locked zone, which is determined by geomorphological, geological, and thermochronological uplift/subsidence data for the period of 1 Myr. Based on 3-D stress data (Terakawa and Matsu'ura 2010), Hashimoto and Terakawa (2018) developed a method of stress data inversion and applied it to obtain a detailed distribution of the collision rate around Izu Peninsula. They obtained a wider locked zone, closer to Boso Peninsula, with a low collision rate $(\leq 0.4)$.

To test the effect of a different locked zone, we set a locked zone after Hashimoto and Terakawa (2018), with a uniform collision rate of 0.3 , and calculated the stress rates (Additional file 1: Figs. S3-S6). Focusing on the east side of Boso Peninsula, the calculated stress pattern is allaround horizontal extension to normal type (Additional file 1: Fig. S3), showing only small differences with our model (Fig. 3). The effect of the collision is strong near the edge of the locked zone but rapidly decreases to the east. We also examine the match between the calculated stress rates and the observed moment tensors in terms of $\triangle \mathrm{CFF}$ (Additional file 1: Figs. S4 and S5) and of normalized tensor dot product (Additional file 1: Fig. S6). The results are also similar to our results (Fig. 4 and Additional file 1: Figs. S1, S2). Therefore, for both locked zone settings, earthquake occurrence under Boso Peninsula appears to be dominated by the subduction effect rather than the collision effect.

In Fig. 5, we attempt to show the separate contributions of PAC and PHS plate subduction to the regional stress. Figure $5 \mathrm{a}$, b shows the map-view visualization of the PAC and PHS subduction effects at $30 \mathrm{~km}$ depth. Figure $5 \mathrm{c}$, $\mathrm{d}$ shows cross-sectional views through Boso Peninsula normal to their respective trenches. We can see that normal-type earthquakes with east-west extension develop with PAC subduction (Fig. 5a, c). Similarly, north-south extension develops with PHS subduction except around 


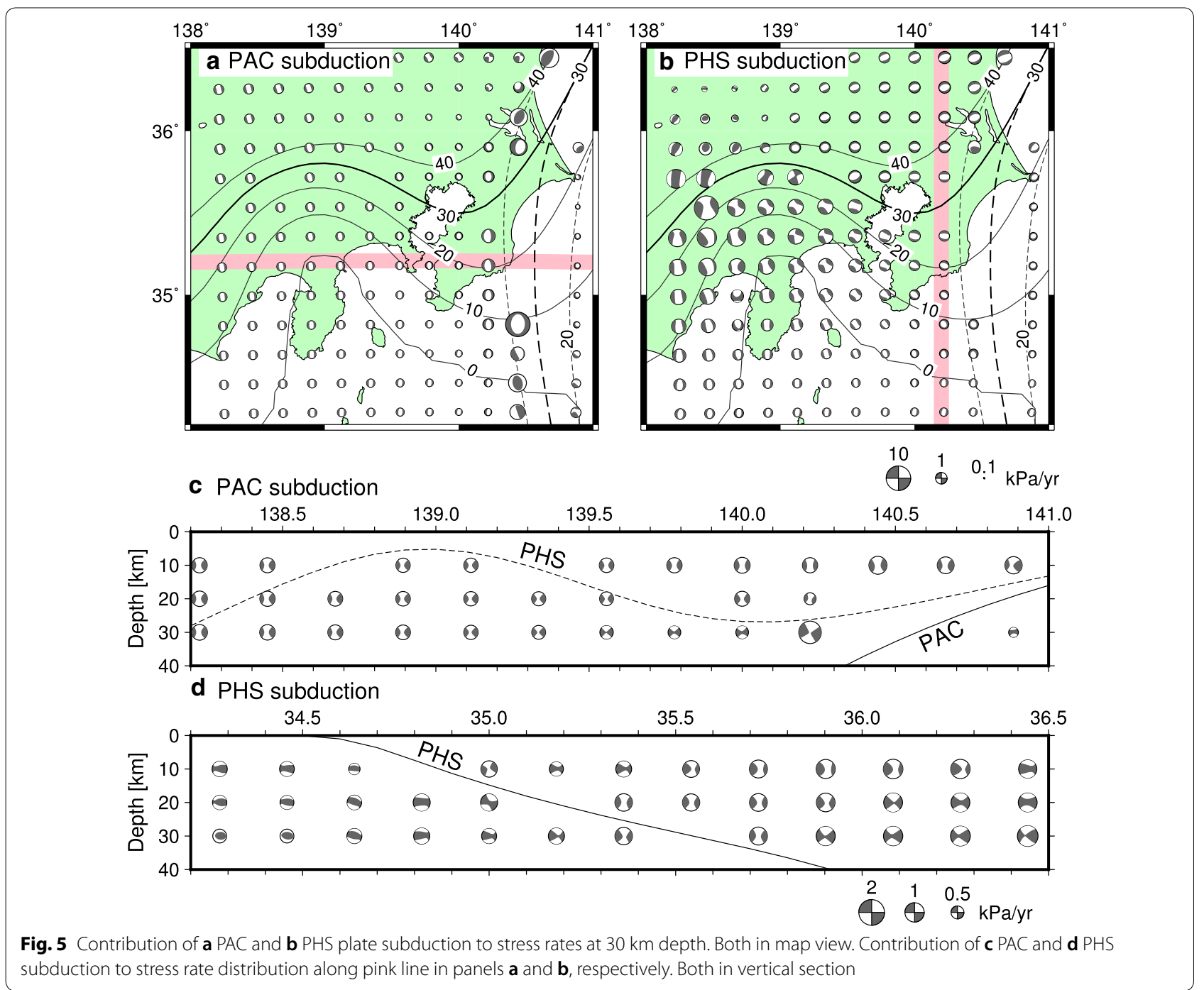

Izu Peninsula, where the geometrical effect of the plate interface appears to dominate (Fig. 5b, d). Thus, the development of 'doughnut-type' all-around horizontal extension around Boso (Fig. 3c) is explained by the superposition of both PAC and PHS plate subduction.

Fukahata and Matsu'ura (2016) theoretically investigated the mechanism of stress development in subduction zones using the dislocation model. They found that extensional stress develops above the 2-D plate interface depending on its curvature, which is normally convex upward. Away from the plate interface, stress fields in their solution are antisymmetric about the mid-plane as elastic flexure problems (Watts 2001). In our results, however, PAC and PHS plate subduction is simply extensional at any depth away from the trench (Fig. 5c, d), which may be a result of the curved 3-D geometry of the plate interface. As Eq. (1) shows, the stress fields consist of the integrated effects of slip distributed over the plate interface. In purely 2-D plate geometry cases, the near- and far-field effects of slip over the plate interface cancel out, leaving a small vertical stress variation. In the case of 3-D plate geometry, however, the two effects do not cancel out, and the near-field effect of slips from nearby areas (within $\sim 100 \mathrm{~km}$ ), which are presumably extensional, may dominate. This lateral variation may be stronger than the subtle vertical variation that appears in 2-D cases, resulting in the stress fields depicted in Fig. 5c, d. 


\section{Conclusions}

To explain the occurrence of normal-type earthquakes in the PHS slab under Boso Peninsula, we calculate stress rates in the slab and in the surrounding area, using our previous dislocation model for plate subduction. Calculated stress rates under Boso Peninsula are horizontally extensional both above and below the PHS plate interface. We apply these stress rates to the nodal planes of observed earthquakes to calculate the Coulomb failure function, $\triangle C F F$. Calculated $\triangle C F F$ s are generally positive on normal-fault type earthquakes under Boso Peninsula, indicating that the calculated stress rates are favorable for slip. $\triangle$ CFFs are also consistent with the earthquake occurrence pattern in adjacent, seismically active areas within the PHS and EUR plates, which supports our stress loading model. Calculation of the individual contributions of PAC and PHS plate subduction shows that stress loading from neither plate alone is sufficient to generate the stress field under Boso Peninsula, and that the contribution of both plates is necessary. The collision of Izu Peninsula has little influence on stress around Boso.

\section{Supplementary information}

Supplementary information accompanies this paper at https://doi. org/10.1186/s40623-020-01201-6.

Additional file 1. Additional figures.

\section{Abbreviations}

PAC: Pacific; PHS: Philippine Sea; EUR: Eurasian; $\triangle$ CFF: Coulomb failure function.

\section{Acknowledgements}

We would like to thank Editor Ryosuke Ando and two anonymous reviewers for improving the manuscripts. We are grateful to Anne D. Van Horne for her constructive comments and grammatical correction. We thank National Research Institute for Earth and Disaster Resilience for providing F-net focal moment tensor data. Figures were prepared with the use of Generic Mapping Tool (Wessel and Smith 1998).

\section{Authors' contributions}

$\mathrm{AH}$ performed the computations and prepared the manuscript. HS contributed to the interpretation of the results. TS contributed to the modeling and the interpretation of the results. All authors read and approved the final manuscript.

\section{Funding}

This study was supported by JSPS KAKENHI Grant Number 19K04033, and the Integrated Research Project on Seismic and Tsunami hazards around the Sea of Japan.

\section{Availability of data and materials}

The data of the moment tensors are available from F-net focal mechanism catalog of National Research Institute for Earth and Disaster Resilience (NIED) (http://www.fnet.bosai.go.jp/). The calculated stress rates are available from the corresponding author on reasonable request.

\section{Ethics approval and consent to participate}

Not applicable.

\section{Consent for publication}

Not applicable.

\section{Competing interests}

The authors declare that they have no competing interests.

\section{Author details}

${ }^{1}$ Earthquake Research Institute, University of Tokyo, Yayoi 1-1-1, Bunkyo-ku, Tokyo 113-0032, Japan. ${ }^{2}$ Department of Earth Sciences, Graduate School of Science, Chiba University, Chiba 263-8522, Japan.

Received: 6 November 2019 Accepted: 19 May 2020

Published online: 03 June 2020

\section{References}

Christensen DH, Ruff LJ (1988) Seismic coupling and outer rise earthquakes. J Geophys Res 93:13421-13444

DeMets C, Gordon RG, Argus DF, Stein S (1994) Effect of recent revisions to the geomagnetic reversal time scale on estimates of current plate motions. Geophys Res Lett 21:2191-2194

Ekström G, Nettles M, Dziewoński AM (2012) The global CMT project 2004-2010: centroid-moment tensors for 13,017 earthquakes. Phys Earth Planet Inter 200-201:1-9

Engdahl ER, Scholz CH (1977) A double Benioff Zone beneath the central Aleutians: an unbending of the lithosphere. Geophys Res Lett 4:473-476

Enns A, Becker TW, Schmeling H (2005) Influence of trench width on subduction hinge retreat rates in 3-D models of slab rollback. Geophys J Int 160:761-775

Fukahata Y, Matsu'ura M (2005) General expressions for internal deformation fields due to a dislocation source in a multilayered elastic half-space. Geophys J Int 161:507-521

Fukahata Y, Matsu'ura M (2006) Quasi-static internal deformation due to a dislocation source in a multilayered elastic/viscoelastic half-space and an equivalence theorem. Geophys J Int 166:418-434

Fukahata Y, Matsu'ura M (2016) Deformation of island-arc lithosphere due to steady plate subduction. Geophys J Int 204:825-840

Funiciello F, Morra G, Regenauer-Lieb K, Giardini D (2003) Dynamics of retreating slabs: 1. Insights from two-dimensional numerical experiments. J Geophys Res 108:2206. https://doi.org/10.1029/2001JB000898

Hasegawa A, Umino N, Takagi A (1978) Double-planed structure of the deep seismic zone in the northeastern Japan arc. Tectonophysics 47:43-58

Hashima A, Fukahata Y, Matsu'ura M (2008a) 3-D simulation of tectonic evolution of the Mariana arc-back-arc system with a coupled model of plate subduction and back-arc spreading. Tectonophysics 458:127-136

Hashima A, Takada Y, Fukahata Y, Matsu'ura M (2008b) General expressions for internal deformation due to a moment tensor in an elastic/viscoelastic multilayered half-space. Geophys J Int 175:992-1012

Hashima A, Fukahata Y, Hashimoto C, Matsu'ura M (2014) Quasi-static strain and stress fields due to a moment tensor in elastic-viscoelastic layered half-space. Pure Appl Geophys 171:1669-1693

Hashima A, Sato T, Sato H, Asao K, Furuya H, Yamamoto S, Kameo K, Miyauchi T, Tsumura N, Kaneda H (2016) Simulation of tectonic evolution of the Kanto Basin of Japan since 1 Ma due to subduction of the Pacific and Philippine Sea plates and the collision of the Izu-Bonin arc. Tectonophysics 679:1-14

Hashimoto C, Matsu'ura M (2006) 3-D simulation of tectonic loading at convergent plate boundary zones: internal stress fields in northeast Japan. Pure Appl Geophys 163:1803-1817

Hashimoto C, Terakawa T (2018) Stress data inversion to estimate collision rate distribution and its application to the Izu Peninsula, Japan. Tectonophysics 744:47-57

Hashimoto C, Fukui K, Matsu'ura M (2004) 3-D modelling of plate interfaces and numerical simulation of long-term crustal deformation in and around Japan. Pure Appl Geophys 161:2053-2068

Holt AF, Royden LH, Becker TW, Faccenna C (2018) Slab interactions in 3-D subduction settings: the Philippine Sea Plate region. Earth Planet Sci Lett 489:72-83

Imanishi K, Ando R, Kuwahara Y (2012) Unusual shallow normal-faulting earthquake sequence in compressional northeast Japan activated after 
the 2011 off the Pacific coast of Tohoku earthquake. Geophys Res Lett 39:L09306. https://doi.org/10.1029/2012GL051491

Imanishi K, Uchide T, Ohtani M, Matsushita R, Nakai M (2019) Construction of the crustal stress map in the Kanto Region, central Japan. Bull Geol Surv Jpn 70:273-298 (in Japanese with English abstract)

Ishibe T, Shimazaki K, Satake K, Tsuruoka H (2011) Change in seismicity beneath the Tokyo metropolitan area due to the 2011 off the Pacific coast of Tohoku Earthquake. Earth Planets Space 63:731-735. https://doi. org/10.5047/eps.2011.06.001

Ishibe T, Satake K, Sakai S, Shimazaki K, Tsuruoka H, Yokota Y, Nakagawa S, Hirata N (2015) Correlation between Coulomb stress imparted by the 2011 Tohoku-Oki earthquake and seismicity rate change in Kanto, Japan. Geophys J Int 201:112-134

Koike K, Machida H (2001) Atlas of Quaternary marine terraces in the Japanese Islands. Univ Tokyo Press, Tokyo (in Japanese)

Matsuda T (1977) Tertiary and quaternary tectonism of Japan in relation to plate motions. Monogr Assoc Geol Collab J.jn 20:213-225 (in Japanese with English abstract)

Matsuda T (1978) Collision of the Izu-Bonin arc with central Honshu: cenozoic tectonics of the Fossa Magna, Japan. J Phys Earth 26(Suppl.):S409-S421

Matsuda T (1991) Late cenozoic strata. In: Hashimoto M (ed) Geology of Japan. Terra Scientific Publishing Company, Tokyo, pp 87-114

Matsu'ura M, Sato T (1989) A dislocation model for the earthquake cycle at convergent plate boundaries. Geophys J Int 96:23-32

Matsu'ura M, Noda A, Fukahata Y (2007) Geodetic data inversion based on Bayesian formulation with direct and indirect prior information. Geophys J Int 171:1342-1351

Nakajima J, Hasegawa A (2010) Cause of M7 earthquakes beneath the Tokyo metropolitan area, Japan: possible evidence for a vertical tear at the easternmost portion of the Philippine Sea slab. J Geophys Res 115:B04301. https://doi.org/10.1029/2009JB006863

Nakajima J, Hirose F, Hasegawa A (2009) Seismotectonics beneath the Tokyo metropolitan area, Japan: effect of slab-slab contact and overlap on seismicity. J Geophys Res 114:B08309. https://doi.org/10.1029/2008JB006101

Nakajima J, Hasegawa A, Hirose F (2011) Stress regime in the Philippine Sea slab beneath Kanto, Japan. Geophys Res Lett 38:L16318. https://doi. org/10.1029/2011GL048754

Okada Y, Kasahara K (1990) Earthquake of 1987, off Chiba, central Japan and possible triggering of eastern Tokyo earthquake of 1988. Tectonophysics 172:351-364

Okada Y, Kasahara K, Hori S, Obara K, Sekiguchi S, Fujiwara H, Yamamoto A (2004) Recent progress of seismic observation networks in Japan
-Hi-net, F-net, K-NET and KiK-net. Earth Planets Space 56:15-28. https:// doi.org/10.1186/BF03353076

Ozawa S, Miyazaki S, Hatanaka Y, Imakiire T, Kaidzu M, Murakami M (2003) Characteristic silent earthquakes in the eastern part of the Boso peninsula, Central Japan. Geophys Res Lett 30:1283. https://doi.org/10.1029/2002G L016665

Sato H (1994) The relationship between late Cenozoic tectonic events and stress field and basin development in northeast Japan. J Geophys Res 99:22261-22274

Sato T, Matsu'ura M (1988) A kinematic model for deformation of the lithosphere at subduction zones. J Geophys Res 93:6410-6418

Sato T, Higuchi H, Miyauchi T, Endo K, Tsumura N, Ito T, Noda A, Matsu'ura M (2016) The source model and recurrence interval of Genroku-type Kanto earthquakes estimated from paleo-shoreline data. Earth Planets Space 68:17. https://doi.org/10.1186/s40623-016-0395-3

Sato T, Hasegawa S, Kono A, Shiobara H, Yagi T, Yamada T, Shinohara M, Usui N (2017) Detection of vertical motion during a slow-slip event off the Boso Peninsula, Japan, by ocean bottom pressure gauges. Geophys Res Lett 44:2710-2715

Seno T, Yoshida M (2004) Where and why do large shallow intraslab earthquakes occur? Phys Earth Planet Inter 141:183-206

Smith WHF, Sandwell DT (1997) Global sea floor topography from satellite altimetry and ship depth soundings. Science 277:1956-1962

Sugimura S (1972) Plate boundaries around Japan. Kagaku (Science) 42:192-202 (in Japanese)

Takada Y, Matsu'ura M (2004) A unified interpretation of vertical movement in Himalaya and horizontal deformation in Tibet on the basis of elastic and viscoelastic dislocation theory. Tectonophysics 383:105-131

Terakawa T, Matsu'ura M (2010) The 3-D tectonic stress fields in and around Japan inverted from centroid moment tensor data of seismic events. Tectonics 29:TC6008. https://doi.org/10.1029/2009TC002626

Watts AB (2001) Isostasy and flexure of the lithosphere. Cambridge Univ Press, Cambridge

Wessel P, Smith WHF (1998) New, improved version of the generic mapping tools released. EOS Trans AGU 79:579

\section{Publisher's Note}

Springer Nature remains neutral with regard to jurisdictional claims in published maps and institutional affiliations.

\section{Submit your manuscript to a SpringerOpen ${ }^{\circ}$ journal and benefit from:}

- Convenient online submission

- Rigorous peer review

- Open access: articles freely available online

- High visibility within the field

- Retaining the copyright to your article

Submit your next manuscript at $\boldsymbol{\nabla}$ springeropen.com 